\title{
Spermatic Cord Anastomotic Leak, CTCAE
}

National Cancer Institute

\section{Source}

National Cancer Institute. Spermatic Cord Anastomotic Leak, CT CAE. NCI Thesaurus.

Code C143855.

A finding of leakage due to breakdown of a spermatic cord anastomosis (surgical connection of two separate anatomic structures). 